\title{
Sebuah Fenomena Bank Syariah di Kota Santri
}

\author{
Wenda Wahyu Christiyanto ${ }^{1 *}$, Mardi Astutik ${ }^{2}$ \\ Sekolah Tinggi Ilmu Ekonomi (STIE) PGRI Dewantara Jombang ${ }^{2}$ \\ *Korespondensi: wenda.christiyanto@gmail.com
}

Diserahkan: 2 Pebruari 2018, Direvisi: 15 Pebruari 2018, Diterima: 3 Maret 2018

\begin{abstract}
In last 20 years, Islamic Banking has been operating in Indonesia. It Begun when Bank Muamalat Indonesia established in 1992, then followed by the others. By over 250 million populations in Indonesia, including a large number of muslim as majority, Indonesia should be a promising market for Islamic Banking. Nonetheles, Islamic Banks, which is supposed to be muslim icon, are not capable to do much in the biggest muslim population country. Besides two decades, Islamic Banks still have not been able to offset the domination of Conventional Banks, it just only have less than 5 percent of banking market share. Depend on the phenomenon, this study intens to investigate Islamic Banks looked from marketing aspect. This study was conducted in Jombang, that's known as santri city. Jombang is considered to reflect the national condition with a smaller scale, because this city has a large number Muslim population with a thick Islamic culture. This study purposes to conclude the impact of contemporary marketing mix on the interest of community to be customers of Islamic Banks, with brand image as the mediation variable. This study was conducted by survey method, then the informations were analyzed by SEMPLS technique using WarpPLS 5.0. The result show that the data has met the rules of outer model, inner model and model fit. The results in this research signify that contemporary marketing mix leads the public interest to be customer of Islamic Banks, with brand image as partial mediating variable.

Keywords: Contemporary Marketing Mix, Brand, Image, Buying Interest, Islamic Banking.
\end{abstract}

\begin{abstract}
Abstrak
Bank Syariah telah beroperasi di Indonesia selama kurang lebih 20 tahun di Indonesia. Tonggak awal Bank Syariah di Indonesia ditandai dengan mulai beroperasinya Bank Muamalat pada tahun 1992, kemudian diikuti oleh Bank Syariah lainnya. Dengan penduduk Indonesia yang saat ini berjumlah lebih dari 250 juta jiwa, dengan mayoritas muslim, seharusnya hal itu menjadi pasar potensial Bank Syariah. Namun ternyata Bank Syariah belum mampu mengimbangi dominasi Bank Konvensional. Selama 20 tahun lebih beroperasi di Indonesia, Bank Syariah hanya mampu menembus 5\% pangsa pasar perbankan. Berdasarkan fenomena tersebut, maka penelitian ini berupaya untuk menganalisa Bank Syariah dari aspek pemasarannya. Penelitian ini dilakukan di Jombang, yang juga disebut sebagai kota santri. Kota Jombang dianggap dapat merefleksikan fenomena yang ada dalam skala nasional, karena Jombang penduduknya mayoritas muslim dengan budaya Islamnya yang kental. Penelitian ini berupaya untuk menganalisa pengaruh Contemporary Marketing Mix terhadap minat masyrakat untuk menjadi nasabah Bank Syariah, dengan Brand Image sebagai variabel mediasi. Penelitian ini menggunakan metode survey, serta menggunakan teknik SEM-PLS dengan alat WarpPLS 5.0 untuk analisa data. Hasil analisa telah memenuhi asumsi outer model, inner model dan model fit, serta menunjukkan bahwa Contemporary Marketing Mix mempengaruhi minat beli, dengan Brand Image sebagai variabel mediasi parsial.
\end{abstract}

Kata Kunci: Contemporary Marketing Mix, Brand, Minat Beli, Bank Syariah.

\section{A. PENDAHULUAN}

Saat ini peran perbankan dalam pergerakan perekonomian khususnya di Indonesia sangat vital, hal ini dikarenakan peran utama lembaga perbankan sebagai intermediator keuangan. Bank merupakan institusi yang bertugas menerima simpanan uang masyarakat, menyalurkan uang kepada masyarakat dan melayani jasa keuangan (Karim 
2013). Sedangkan menurut UU No.10 tahun 1998 tentang Perbankan, Bank adalah institusi yang menghimpun dana masyarakat serta menyalurkannya kepada masyarakat dalam upaya meningkatkan kesejahteraan masyarakat.

Selain sebagai financial intermediary, Bank juga mempunyai fungsi sebagai trust agent, development agent dan services agent (Triandaru dan Budisantoso 2009). Sebagai trust agent, Bank harus memiliki amanah dalam menyimpan dan mengelola dengan baik uang yang dititipkan di Bank tersebut. Begitu pula dalam penyaluran dana, Bank harus memegang prinsip kehati-hatian dalam menyalurkan dana kepada debitur. Sebagai development agent, Bank dapat mengakomodir masyarakat dalam kegiatan investasi, distribusi dan konsumsi. Sebagai services agent, Bank menyediakan jasa pengiriman uang, penitipan barang berharga, bank garansi dan jasa terkait lainnya.

Berdasarkan UU No. 10 Tahun 1998 tentang Perbankan, Bank dikategorikan menjadi dua (2) menurut jenisnya, yaitu Bank Umum dan Bank Perkreditan Rakyat. Bank Umum adalah bank yang beroperasi secara konvensional atau syariah, dengan menyediakan jasa lalu lintas pembayaran, sedangkan Bank Perkreditan Rakyat adalah bank yang melakukan operasional usahanya secara konvensional atau syariah, tanpa menyediakan jasa dalam lalu lintas pembayaran.

Dalam perkembangan selanjutnya, muncul dan berkembang beberapa Bank yang menyatakan sebagai Bank Syariah, sebagai tonggaknya yaitu Bank Muamalat Indonesia yang berdiri tahun 1992, kemudian Bank Syariah Mandiri yang mulai beroperasi pada tahun 1999, serta bank syariah lainnya, baik Bank Umum Syariah (BUS) maupun Unit Usaha Syariah (UUS). Dengan semakin berkembangnya Bank Syariah di Indonesia, mendorong pemerintah untuk mengatur kegiatan Bank Syariah, yang tertuang pada UU No. 21 Tahun 2008 tentang Perbankan Syariah, di mana Bank Syariah digambarkan sebagai suatu bank yang operasionalnya menggunakan prinsip syariah, yang terdiri dari Bank Umum Syariah (BUS) dan Bank Pembiayaan Rakyat Syariah (BPRS).

Tabel 1. Perkembangan Perbankan Syariah di Indonesia

\begin{tabular}{cccccc}
\hline \hline Indikator & $\mathbf{2 0 1 1}$ & $\mathbf{2 0 1 2}$ & $\mathbf{2 0 1 3}$ & $\mathbf{2 0 1 4}$ & $\mathbf{2 0 1 5}$ \\
\hline \hline Jumlah jaringan kantor & 1739 & 2262 & 2588 & 2517 & 2301 \\
\hline Total aset (Rp Trilliun) & 145 & 195 & 242 & 272 & 296 \\
\hline Market share & $3.98 \%$ & $4,58 \%$ & $4,89 \%$ & $4,85 \%$ & $4,86 \%$ \\
\hline \hline
\end{tabular}

Sumber: OJK, 2016

Berdasarkan tabel di atas, diketahui bahwa total aset Bank Syariah semakin berkembang setiap tahunnya. Hal ini mengindikasikan bahwa, semakin hari masyarakat Indonesia semakin banyak yang menggunakan jasa perbankan syariah, entah itu membuka akun yang baru di bank syariah, atau memindahkan akunnya ke Bank Syariah, dari akun sebelumnya di Bank Konvensional. Namun, sepanjang 25 tahun perjalanannya di Indonesia, Bank Syariah masih belum bisa mengungguli atau menyamai market share Bank Konvensional. Yang memprihatinkan adalah, ternyata market share Bank Syariah berkisar di bawah 5\%. Ini menunjukkan dominasi Bank Konvensional yang sangat kuat, dengan penguasaan 95\% market share perbankan Indonesia. Sungguh ironis, Indonesia dengan penduduknya yang mayoritas muslim sebesar 87,18\% atau sebesar 207.176.162 jiwa (Badan Pusat Statistik, 2011) yang seharusnya mendukung pertumbuhan Bank Syariah di Indonesia.

Dari gambaran besar tersebut, peneliti berencana untuk melihat fenomena pada luasan wilayah yang lebih kecil, yaitu di Kabupaten Jombang, Provinsi Jawa Timur. 
Kota Jombang dikenal sebagai Kota Santri, dengan penduduknya mayoritas beragama muslim, serta tersebar berbagai pondok pesantren, sehingga Kota Jombang merupakan pasar potensial bagi Bank Syariah. Sejak tahun 2005, Bank Syariah sudah mulai beroperasi di Kota Jombang, diawali oleh BPRS Lantabur. Kemudian Bank Syariah Mandiri, Bank Muamalat Indonesia serta Bank Syariah lainnya mulai beroperasi di Kota Jombang pada tahun 2008. Namun, kondisi persaingan dan market share antara Bank Konvensional dan Bank Syariah di Kota Jombang tidak jauh berbeda dengan kondisi nasional.

Fenomena yang terjadi mengindikasikan bahwa minat masyarakat terhadap produk dan jasa Bank Syariah masih rendah. Minat beli masyarakat dapat dipengaruhi oleh Contemporary Marketing Mix dan Brand Image. Hal tersebut tertuang dalam penelitian yang dilakukan Margaretha (2011), di mana menghasilkan kesimpulan bahwa Contemporary Marketing Mix Jasa dengan dimensi Product, Price, Physical Evidence dan Process memiliki pengaruh terhadap minat beli, sedangkan Place, Promotion dan People tidak memiliki pengaruh. Pada Tahun 2010, Setiadi menyimpulkan dalam penelitiannya bahwa Place memberikan pengaruh paling besar terhadap Brand Image, disusul secara berurutan dengan Product, People, Process dan Promotion, sedangkan Price dan Physical Evidence memiliki pengaruh yang negatif terhadap Brand Image. Sedangkan Maunaza (2012) menyatakan bahwa Brand Image berpengaruh terhadap minat beli konsumen.

Berdasarkan penelitian yang telah dilakukan sebelumnya, peneliti tertarik untuk mengkaji tentang Pengaruh Contemporary Marketing Mix terhadap Minat Beli Konsumen dengan Brand Image sebagai Variabel Mediasi. Fenomena tersebut menarik untuk dikaji lebih lanjut, karena penelitian tentang Perbankan masih didominasi pada aspek keuangan, sedangkan aspek pemasaran masih jarang dilakukan, terlebih pada Perbankan Syariah yang masih dalam tahap pengembangan. Dari hal tersebut timbul pertanyaan dari peneliti tentang apakah Contemporary Marketing Mix, berpengaruh terhadap minat masyarakat untuk berbank syariah, dengan Brand Image sebagai variabel mediasinya. Adapun penelitian ini dilakukan masih terbatas dalam skala kecil, yaitu di wilayah Kabupaten Jombang.

\section{B. LANDASAN TEORI Bank Syariah}

Bank Syariah adalah bank yang dalam operasional usahanya meninggalkan riba (Machmud dan Rukmana, 2010). Adapun pendapat lainnya menyatakan bahwa Bank Syariah adalah Bank yang dalam aktivitasnya atas dasar prinsip syariah (Triandaru dan Budisantoso, 2009). Sedangkan menurut UU No. 21 Tahun 2008 tentang Perbankan Syariah, Bank Syariah merupakan Bank yang beroperasi berdasarkan prinsip syariah, yang terdiri dari Bank Umum Syariah (BUS) dan Bank Pembiayaan Rakyat Syariah (BPRS). Jadi dengan kata lain bahwa Bank Syariah adalah Bank yang dalam setiap operasional usahanya menggunakan prinsip syariah.

\section{Contemporary Marketing Mix}

Bauran pemasaran adalah seperangkat alat yang dapat digunakan untuk membentuk karakteristik produk oleh pemasar, dalam kaitannya adalah produk yang ditawarkan kepada para pelanggan (Tjiptono, 2015). Bauran pemasaran juga merupakan alat yang terdiri dari berbagai unsur program pemasaran dan penentuan posisi yang ditetapkan, sehingga kegiatan pemasaram dapat berjalan dengan sukses (Lupiyoadi, 2013). Dari pendapat ahli di atas maka dapat disimpulkan bahwa bauran pemasaran 
merupakan seperangkat alat yang terdiri dari berbagai unsur yang dapat digunakan oleh pemasar untuk membentuk karakteristik suatu produk.

Marketing mix atau bauran pemasaran yang telah kita kenal adalah 4P. Namun karena dalam perkembangannya, ternyata 4P masih dirasa kurang mencukupi. Hal ini disebabkan karena adanya perkembangan jasa saat ini, sehingga diperlukan perlakuan yang berbeda. Terkait dengan uraian tersebut, maka bauran pemasaran, khususnya unuk jasa menurut Tjiptono (2015) terdiri atas 8P, yaitu Product (Produk), Price (Harga), Promotion (Promosi), Place (Tempat/lokasi), People (Sumber Daya Manusia), Physical Evidence (Bukti fisik), Process (Proses), dan Customer Service (Pelayanan terhadap pelanggan).

Menurut Booms dan Bitner dalam Setiadi (2010), terdapat tujuh (7) hal (7 P's) dalam Contemporary Marketing Mix atau bauran pemasaran jasa dan dapat dicirikan pada tabel kerangka kerja Booms dan Bitner sebagai berikut :

Tabel 2. Kerangka Kerja Booms dan Bitner

\begin{tabular}{ll}
\hline \hline \multicolumn{1}{c}{ Indikator } & \multicolumn{1}{c}{ Bauran Pemasaran yang domodifikasi dan diperluas } \\
\hline \hline Elemen 7 Ps & $\begin{array}{l}\text { Kualitas, nama merek, jenis jasa, jaminan, kapabilitas, facilitating } \\
\text { goods, bukti nyata, harga, staff, lingkungan fisik, proses } \\
\text { pengiriman layanan }\end{array}$ \\
\hline Product & $\begin{array}{l}\text { Tingkat harga, diskon, payment terms, interaksi harga diferensiasi } \\
\text { Price }\end{array}$ \\
\hline Place & Lokasi, aksesibilitas, chanel distribusi, cakupan wilayah \\
\hline Promotion & $\begin{array}{l}\text { Staf, pelatihan, penampilan, perilaku interpersona, sikap, } \\
\text { keterlibatan, kontak dengan pelanggan }\end{array}$ \\
\hline People & $\begin{array}{l}\text { Lingkungan, furnishing, warna, tata letak, tingkat kebisingan, } \\
\text { bukti nyata }\end{array}$ \\
\hline Physical & $\begin{array}{l}\text { Kebijakan prosedur, mekanisasi, kecermatan karyawan, } \\
\text { Evidence }\end{array}$ \\
\hline \hline
\end{tabular}

Sumber: Booms dan Bitner 1981, dalam Setiadi 2010

\section{Brand Image}

Banyak Penelitian yang membahas tentang Brand Image, antara lain penelitian yang dilakukan oleh Istiyanto, B., \& Nugroho, L. (2017) tentang Analisis Pengaruh Brand Image, Harga, Dan Kualitas Produk Terhadap Keputusan Pembelian Mobil. Brand image adalah persepsi dan keyakinan konsumen, yang tercermin sebagai asosiasi di dalam ingatan konsumen (Kotler dan Keller, 2009). Nulufi (2015) mengemukakan pendapat tentang brand image sebagai serangkaian diskripsi tentang asosiasi dan keyakinan konsumen kepada sebuah merek tertentu. Sedangkan menurut Setiadi (2010), brand image adalah pencitraan merek terhadap suatu kesan tertentu terkait kebiasaan, manfaat atribut produk, gaya hidup, harga, geografis, pesaing, artis dll. Dari berbagai pengertian tersebut, maka dapat dikatakan bahwa brand image adalah segala sesuatu yang melekat dan yang terekam dalam benak konsumen terkait suatu merek, berdasarkan pengalaman atau informasi atas merek tersebut.

Dalam pengukuran variabel brand image diperlukan beberapa indikator yang menunjang. Keller (2013) mengatakan bahwa, creating a positive brand image takes marketing programs that link strong, favourable, and unique associations to the brand in memory, yang artinya menciptakan sebuah citra merek yang positif membutuhkan 
program-program pemasaran yang berkaitan kesan-kesan yang kuat, baik dan unik tentang merek di ingatan konsumen. Nulufi (2015) menggunakan indikator berikut untuk mengukur brand image, yaitu quality, awareness, kepribadian dan citra diri. Oktaviani (2014) menggunakan Citra perusahaan, Citra produk dan Populer sebagai indikator brand image. Seftiani (2014) menggunakan Mudah dikenali, Digemari dan Terkenal sebagai indikator dari Brand Image. Sedangkan Strenght of Brand Association, Favourability of Brand Association dan Uniqueness of Brand Association digunakan Maunaza (2012) sebagai indikator untuk mengukur brand image. Dari berbagai indikator di atas, penulis menggabungkan beberapa indikator untuk mengukur brand image, yaitu Strenght of Brand Association, Favourability of Brand Association dan Uniqueness of Brand Association.

\section{Minat Beli Konsumen}

Minat merupakan salah satu aspek psikologis yang berpengaruh dengan intensitas yang cukup besar, terhadap sikap perilaku (Schiffman dan Kanuk, 2008). Sedangkan Minat beli adalah sebuah perilaku konsumen yang merupakan respon terhadap obyek yang menunjukkan tentang keinginan pelanggan untuk membeli suatu produk (Kotler dan Keller, 2009). Minat beli muncul karena adanya proses belajar sehingga tercipta motivasi konsumen untuk memenuhi kebutuhannya dan merupakan aspek psikologis yang mempengaruhi sikap dan perilakunya untuk membeli sebuah produk berdasarkan informasi yang diperolehnya (Nulufi, 2015). Dari berbagai pengertian di atas, maka dapat dikatakan bahwa minat beli adalah respon psikologis konsumen terhadap suatu produk yang digunakan untuk memenuhi kebutuhannya berdasarkan informasi yang diperolehnya.

Schiffman dan Kanuk (2008) menggunakan ketertarikan untuk mengumpulkan informasi, pertimbangan untuk membeli, tertarik untuk mencoba, keinginan untuk mengetahui lebih jauh tentang produk, dan keinginan untuk memiliki produk sebagai indikator minat beli. Indikator minat beli yang digunakan Nulufi (2015) dalam penelitiannya adalah minat transaksional, minat referensial, minat preferensial dan minat eksploratif. Menurut Margaretha (2011), indikator minat beli adalah minat beli berdasarkan pertimbangan produk, harga, promosi, lokasi, SDM, bukti fisik dan berdasarkan proses. Pada jurnalnya, Rizky dan Yasin (2014) menggunakan Attention, Interest, Desire dan Action (AIDA) sebagai indikator minat beli. Dari berbagai indikator yang dikemukakan di atas, dalam penelitian ini penulis menggunakan indikator untuk mengukur variabel minat beli, yaitu Ketertarikan untuk mencari informasi, Pertimbangan untuk membeli, Ketertarikan untuk mencoba, dan Keinginan untuk mengetahui lebih lanjut tentang produk. Hal ini juga mendukung penelitian yang dilakukan oleh Rohim, A., \& Arvianto, S. (2017)

\section{METODE PENELITIAN}

Penelitian ini dirancang untuk mengetahui dan menjelaskan hubungan antar variabel dengan menguji hipotesis. Desain penelitian ini disebut dengan penelitian kausalitas, yaitu desain penelitian yang disusun untuk meneliti kemungkinan hubungan kausal antar variabel (Sanusi, 2011). Maholtra (2005) menyebut desain penelitian seperti ini sebagai riset kausal untuk mendapatkan bukti hubungan sebab akibat (hubungan kausal).

Lokasi penelitian adalah di wilayah Jombang dengan dimensi waktu cross sectional, yaitu pengumpulan data mengenai sampel yang telah ditentukan dari elemen populasi hanya satu kali (Maholtra, 2005). Sedangkan untuk jenis datanya adalah data 
primer, yaitu data yang pertama kali dikumpulkan dan dicatat oleh peneliti (Sanusi, 2011). Data primer ini diperoleh dengan metode survey, dengan menyebarkan kuesioner kepada responden yang merupakan nasabah Bank Konvensional yang belum pernah menjadi nasabah Bank Syariah di Jombang.

Berdasarakan tujuan dan model penelitian, maka hipotesis yang diangkat pada penelitian ini adalah: Diduga, Contemporary Marketing Mix berpengaruh terhadap minat Minat Beli melalui Brand Image

\section{HASIL DAN PEMBAHASAN}

Hasil pengolahan data dengan menggunakan WarpPLS 5.0, adalah sebagai berikut

Tabel 3. Outer Model First (Lower) Order

\begin{tabular}{|c|c|c|}
\hline & Hasil & Keterangan \\
\hline $\begin{array}{l}\text { Validitas } \\
\text { Konvergen }\end{array}$ & $\begin{array}{l}\text { Nilai muatan faktor } \\
\text { masing-masing indikator } \\
\text { dari dimensi Product, } \\
\text { Price, Place, Promotion, } \\
\text { People, Process dan } \\
\text { Physical Evidence lebih } \\
\text { besar dari } 0,6\end{array}$ & $\begin{array}{l}\text { Validitas Konvergen dapat terpenuhi } \\
\text { apabila nilai muatan faktor lebih besar } \\
\text { dari } 0,5 \text {, dianggap cukup pada jumlah } \\
\text { indikator per variabel tidak besar } \\
\text { (Solimun, 2017) }\end{array}$ \\
\hline $\begin{array}{l}\text { Validitas } \\
\text { Diskriminan }\end{array}$ & $\begin{array}{l}\text { Nilai akar AVE untuk } \\
\text { dimensi Product, Price, } \\
\text { Place, Promotion, } \\
\text { People, Process dan } \\
\text { Physical Evidence lebih } \\
\text { besar dari nilai } \\
\text { korelasinya dengan } \\
\text { variabel lainnya. }\end{array}$ & $\begin{array}{l}\text { Validitas diskriminan bisa terpenuhi } \\
\text { apabila nilai akar AVE lebih besar dari } \\
\text { nilai korelasinya dengan variabel lainnya } \\
\text { (Solimun, 2017) }\end{array}$ \\
\hline Reliabilitas & $\begin{array}{l}\text { Nilai Composite } \\
\text { Reliability \& Cronbach's } \\
\text { Alpha Coefficients untuk } \\
\text { dimensi Product, Price, } \\
\text { Place, Promotion, } \\
\text { People, Process dan } \\
\text { Physical Evidence lebih } \\
\text { besar dari } 0,8\end{array}$ & $\begin{array}{l}\text { Kelompok indikator yang mengukur } \\
\text { sebuah variabel memiliki reliabilitas } \\
\text { komposit yang baik, jika memiliki } \\
\text { Composite Reliability Coefficients lebih } \\
\text { besar atau sama dengan 0,7, walaupun } \\
\text { bukan merupakan standar absolut } \\
\text { (Solimun, 2017). } \\
\text { Kelompok indikator yang mengukur } \\
\text { sebuah variabel memiliki reliabilitas } \\
\text { komposit yang baik, jika memiliki } \\
\text { Cronbach's Alpha Coefficients lebih } \\
\text { besar atau sama dengan 0,6 (Solimun, } \\
\text { 2017) } \\
\text { Nilai Composite Reliability dan } \\
\text { Croncbach's Alpha, keduanya harus } \\
\text { bernilai 0,7 sebagai syarat reliabilitas } \\
\text { (Fornell dan Lacker, 1981 dalam } \\
\text { Sholihin dan Ratmono, 2014) }\end{array}$ \\
\hline
\end{tabular}

Sumber: data diolah, 2017 
Tabel 4. Outer Model Second (Higher) Order

\begin{tabular}{|c|c|c|}
\hline & Hasil & Keterangan \\
\hline $\begin{array}{l}\text { Validitas } \\
\text { Konvergen }\end{array}$ & $\begin{array}{l}\text { Nilai weight untuk setiap } \\
\text { indikator milik variabel } \\
\text { Contemporary Marketing } \\
\text { Mix memiliki nilai } P \text {-value } \\
\text { kurang dari } 0,05 \text { dengan } \\
\text { nilai VIF kurang dari } 3,3 \\
\text { (Formatif). } \\
\text { Nilai muatan faktor masing- } \\
\text { masing indikator milik } \\
\text { variabel Brand Image dan } \\
\text { minat beli lebih besar dari } \\
0,6 \text { (Reflektif) }\end{array}$ & $\begin{array}{l}\text { Evaluasi kelayakan pengukuran variabel laten } \\
\text { formatif menggunakan dua kriteria, yaitu } P \text { - } \\
\text { value dari Weight kurang dari } 0,05 \text { dan nilai } \\
\text { VIF kurang dari } 3,3 \text { (Kock, 2013 dalam } \\
\text { Sholihin dan Ratmono, 2014) } \\
\text { Validitas Konvergen dapat terpenuhi apabila } \\
\text { nilai muatan faktor lebih besar dari } 0,5 \text {, } \\
\text { dianggap cukup pada jumlah indikator per } \\
\text { variabel tidak besar (Solimun, 2017) }\end{array}$ \\
\hline $\begin{array}{l}\text { Validitas } \\
\text { Diskriminan }\end{array}$ & $\begin{array}{l}\text { Nilai akar AVE variabel } \\
\text { Contemporary Marketing } \\
\text { Mix, Brand Image dan } \\
\text { Minat Beli lebih besar dari } \\
\text { nilai korelasinya dengan } \\
\text { variabel lainnya. }\end{array}$ & $\begin{array}{l}\text { Validitas diskriminan bisa terpenuhi apabila } \\
\text { nilai akar AVE lebih besar dari nilai } \\
\text { korelasinya dengan variabel lainnya (Solimun, } \\
\text { 2017) }\end{array}$ \\
\hline Reliabilitas & $\begin{array}{l}\text { Nilai Composite Reliability } \\
\text { \& Cronbach's Alpha } \\
\text { Coefficients dari Variabel } \\
\text { Contemporary Marketing } \\
\text { Mix, Brand Image dan } \\
\text { Minat Beli lebih besar dari } \\
0,8\end{array}$ & $\begin{array}{l}\text { Kelompok indikator yang mengukur sebuah } \\
\text { variabel memiliki reliabilitas komposit yang } \\
\text { baik, jika memiliki Composite Reliability } \\
\text { Coefficients lebih besar atau sama dengan } 0,7 \text {, } \\
\text { walaupun bukan merupakan standar absolut } \\
\text { (Solimun, 2017). } \\
\text { Kelompok indikator yang mengukur sebuah } \\
\text { variabel memiliki reliabilitas komposit yang } \\
\text { baik, jika memiliki Cronbach's Alpha } \\
\text { Coefficients lebih besar atau sama dengan } 0,6 \\
\text { (Solimun, 2017) } \\
\text { Nilai Composite Reliability dan Croncbach's } \\
\text { Alpha, keduanya harus bernilai 0,7 sebagai } \\
\text { syarat reliabilitas (Fornell dan Lacker, 1981 } \\
\text { dalam Sholihin dan Ratmono, 2014) }\end{array}$ \\
\hline
\end{tabular}

Sumber: data diolah, 2017

Tabel 5. Model Fit and Quality Indices

\begin{tabular}{llll}
\hline \hline & Nilai & \multicolumn{1}{c}{ Syarat } & Keterangan \\
\hline \hline APC & $\mathrm{P}<0,001$ & $\mathrm{P}<0,05$ (Sholihin dan Ratmono, 2014) & Terpenuhi \\
\hline ARS & $\mathrm{P}<0,001$ & $\mathrm{P}<0,05$ (Sholihin dan Ratmono, 2014) & Terpenuhi \\
\hline AVIF & 3,349 & $\begin{array}{l}\text { Acceptable if }<=5 \text { (Sholihin dan Ratmono, } \\
\text { 2014) }\end{array}$ & Terpenuhi \\
\hline \hline
\end{tabular}

Sumber: Data diolah, 2017 
Tabel 6. Baron and Kenny Mediation Test

Pengaruh Contemporary Marketing Mix ke Minat

Beli

\begin{tabular}{lll}
\hline \hline & Nilai Beta & P Value \\
\hline Direct Effect & 0,532 & $<0,001$ \\
\hline Indirect Effect & 0,283 & $<0,001$ \\
\hline \hline
\end{tabular}

Sumber: Data diolah, 2017

Tabel 7. Path Coefficients and P Values

\begin{tabular}{llll}
\hline \hline & $\begin{array}{l}\text { Contemporary } \\
\text { Marketing Mix }\end{array}$ & Brand Image & Minat Beli \\
\hline \hline $\begin{array}{l}\text { Contemporary } \\
\text { Marketing Mix }\end{array}$ & & \\
\hline Brand Image & $0,706(<0,001)$ & \\
\hline Minat Beli & $0,283(<0,001)$ & $0,296(<0,001)$ & \\
\hline \hline
\end{tabular}

Sumber: Data diolah, 2017

Tabel 8. Indirect Effects for Path with 2 Segments and P Values

\begin{tabular}{lll}
\hline \hline & $\begin{array}{c}\text { Contemporary } \\
\text { Marketing Mix }\end{array}$ & Brand Image Minat Beli \\
\hline \hline Contemporary & \\
Marketing Mix & \\
\hline Brand Image & \\
\hline Minat Beli & $0,209(<0,001)$ & \\
\hline
\end{tabular}

Sumber: Data diolah, 2017

Tabel 9. R-Squared Coefficients

\begin{tabular}{lcc}
\hline $\begin{array}{l}\text { Contemporary } \\
\text { Marketig } \text { Mix }\end{array}$ & Brand Image & Minat Beli \\
\hline \hline & 0,498 & 0,309 \\
\hline \hline
\end{tabular}

Dari hasil analisis di atas, outer model dan inner model dapat dipenuhi. Hasil dari Baron \& Kenny test dapat diketahui bahwa, variabel Brand Image merupakan variabel pemediasi, meskipun sifatnya hanya sebagai pemediasi parsial. Hal tersebut dikarenakan nilai $P$-Value pada direct effect signifikan, tetapi nilai $P$-Value indirect effect juga signifikan (Baron dan Kenny, 1986 dalam Sholihin dan Ratmono, 2014). Dari hasil tersebut dapat disimpulkan bahwa hipotesis dapat diterima, Contemporary Marketing Mix berpengaruh terhadap Minat Beli, dengan Brand Image sebagai variabel mediasi, meskipun hanya bersifat parsial.

Variabel Contemporary Marketing Mix memiliki dimensi penting dan mempunyai nilai yang baik di mata responden, yaitu people. Hal ini bisa disebabkan karena bisnis perbankan, utamanya perbankan syariah adalah bisnis jasa yang mengedepankan pelayanan prima kepada nasabah. Tentunya pelayanan yang prima tidak lepas dari penampilan dan sikap para pegawainya, terutama bagian frontliner (customer service, teller dan security banking hall). Masyarakat akan tertarik untuk menjadi nasabah suatu bank syariah, karena pegawainya yang ramah dan penampilannya yang terkesan rapi 
dan islami. Meskipun demikian, Bank Syariah di Jombang harus tetap menjaga dan meningkatkan layanannya, dengan cara mengadakan pelatihan secara berkala untuk melatih sikap dan penampilan karyawan, terutama bagian frontliner.

Variabel brand image memiliki indikator yang penting dan memiliki penilaian yang baik dari responden, yaitu uniqueness of brand association. Hal ini disebabkan karena keunikan Bank Syariah dibandingkan Bank Konvensional. Beberapa keunikan Bank Syariah adalah seluruh pegawai perempuan diwajibkan memakai hijab, selalu mengucapkan salam ketika menyambut dan selesai melayani nasabah, logo bank syariah yang dipengaruhi oleh simbol atau tulisan islami, dan beberapa nama produk bank syariah memakai istilah bahasa arab. Meskipun demikian, Bank Syariah di Jombang harus tetap mengedepankan sisi profesionalitasnya untuk menjaga pelayanannya yang prima terhadap nasabah.

Variabel minat beli memiliki indikator penting, yaitu pertimbangan untuk membeli. Hal ini menunjukkan bahwa minat beli masyarakat tidak sekedar tercermin dengan hanya mencari informasi atau mencoba, namun ingin langsung membeli atau menjadi nasabah berdasarkan . Informasi ini harus bisa ditangkap oleh Bank Syariah di Jombang agar bisa segera melakukan tindak lanjut terhadap calon nasabah, sehingga masyarakat Jombang bisa segera menjadi nasabah Bank Syariah.

\section{PENUTUP}

Berdasarkan hasil di atas, adapun simpulannya adalah, Contemporary Marketing Mix berpengaruh terhadap minat masyarakat Jombang untuk menjadi nasabah Bank Syariah, dengan variabel Brand Image sebagai varibel mediasi yang bersifat parsial. Oleh karena itu, Bank Syariah hendaknya memperhatikan dimensi dan indikator penting, yaitu people dan uniqueness brand of association, karena dua hal tersebut merupakan daya tarik untuk mendorong minat masyarakat berbank syariah. Adapun saran dominan dari responden agara Bank Syariah, khususnya di kota Jombang, agar Bank Syariah lebih sering mengadakan kegiatan promosi, sehingga masyarakat lebih mengenal tentang produk dan jasa yang ditawarkan oleh Bank Syariah. Kemudian untuk penelitian selanjutnya, diharapkan bisa menyempurnakan penelitian ini dengan menambahkan variabel lain yang terkait tentang motivasi masyarakat untuk berbank syariah, sehingga bisa membantu Bank Syariah untuk semakin mengembangkan pangsa pasarnya.

\section{DAFTAR PUSTAKA}

BPS. 2011. Kewarganegaraan, Suku Bangsa, Agama dan Bahasa Sehari-hari Penduduk Indonesia : Hasil Sensus Penduduk 2010. Jakarta.

Istiyanto, B., \& Nugroho, L. (2017). Analisis Pengaruh Brand Image, Harga, Dan Kualitas Produk Terhadap Keputusan Pembelian Mobil (Studi Kasus Mobil LCGC di Surakarta). Eksis: Jurnal Riset Ekonomi dan Bisnis, 12(1 Apr).

Karim, A. 2013. Bank Islam: Analisis Fiqih dan Keuangan. Raja Grafindo Persada. Jakarta.

Keller, K. L. 2013. Strategic Brand Management : Building, Mesuring, and Managing Brand Equity Fourth Edition. Pearson Education Limited. Essex.

Kotler, P., Keller, K. L. 2009. Manajemen Pemasaran Edisi 13. Penerbit Erlangga. Jakarta.

Lupiyoadi, R. 2013. Manajemen Pemasaran Jasa. Penerbit Salemba Empat. Jakarta. 
Machmud, A., Rukmana. 2010. Bank Syariah: Teori, Kebijakan dan Studi Empiris di Indonesia. Penerbit Erlangga. Jakarta.

Maholtra, N. 2005. Riset Pemasaran. Indeks. Jakarta.

Margaretha, Y. (2011). Analisis Pengaruah Bauran Pemasaran Jasa terhadap Minat Beli pada Program Magister Manajemen Universitas Kristen Maranatha. Prosiding Semantik 2011. 16 April 2011, Semarang.

Maunaza, A. 2012. Pengaruh Brand Image terhadap Minat Beli Konsumen (Studi pada Maskapai Penerbangan Lion Air sebagai Low Cost Carrier). Skripsi. Fakultas Ilmu Sosial dan Ilmu Politik Universitas Indonesia, Depok.

Nulufi, K. 2015. Minat Beli Sebagai Mediasi Pengaruh Brand Image dan Sikap Konsumen terhadap Keputusan Pembelian Batik di Pekalongan (Studi Kasus pada Konsumen Internasional Batik Center dan Pasar Grosir Setono). Skripsi. Fakultas Ekonomi Universitas Negeri Semarang, Semarang.

OJK. 2016. Modul Training of Trainers Keuangan Syariah. Jakarta.

Oktaviani, L. 2014. Analisis Pengaruh Brand Image (Citra Merek), Kulitas Produk dan Harga terhadap Minat Beli Produk Mie Instan Supermi (Studi Kasus Pada Konsumen Mie Instan Supermi di Kota Semarang). Skripsi. Fakultas Ekonomika dan Bisnis Universitas Diponegoro, Semarang.

Republik Indonesia. Undang-Undang Nomor No. 10 Tahun 1998 tentang Perubahan atas UU No. 7 Tahun 1992 tentang Perbankan. Jakarta.

Republik Indonesia. Undang-Undang Nomor No. 21 Tahun 2008 tentang Perbankan Syariah. Jakarta.

Rizky, M. F., Yasin, H. 2014. Pengaruh Promosi dan Harga terhadap Minat Beli Perumahan Obama PT. Nailah Adi Kurnia Sei Mencirim Medan. Jurnal Manajemen dan Bisnis. 14(02): 135 - 143.

Rohim, A., \& Arvianto, S. (2017). Pengaruh Customer Perceived Value Terhadap Word Of Mouth Dengan Customer Loyalty Sebagai Variabel Mediasi (Study Kasus Di CV Putra Putri). Eksis: Jurnal Riset Ekonomi dan Bisnis, 12(1 Apr).

Sanusi, A. 2011. Metodologi Penelitian Bisnis. Penerbit Salemba Empat. Jakarta.

Schiffman, L., Kanuk, L.L. 2008. Perilaku Konsumen. Indeks. Jakarta.

Seftiani, R. 2014. Pengaruh Brand Image, Kualitas Poduk terhadap Brand Prefference dan Implikasinya terhadap Minat Loyalitas (Studi pada Konsumen The Body Shop di Kota Semarang). Skripsi. Fakultas Ekonomika dan Bisnis Universitas Diponegoro, Semarang.

Setiadi, D. 2010. Analisis Pengaruh Bauran Pemasaran Jasa terhadap Brand Image pada Lembaga Kursus Bahasa Inggris ILP (International Language Program) Cabang Bogor. Skripsi. Fakultas Ekonomi dan Manajemen Institut Pertanian Bogor, Bogor.

Sholihin, M., Ratmono, D. (2014). Analisis SEM-PLS dengan WarpPLS 3.0 untuk Hubungan Nonlinier dalam Penelitian Sosial dan Bisnis. Penerbit Andi. Yogyakarta.

Solimun. 2017. Penguatan Confirmatory Research: Pemodelan Persamaan Struktural Pendekatan WarpPLS. Universitas Brawijaya. Malang.

Tjiptono, F. 2015. Pemasaran Jasa. Andi Offset. Yogyakarta.

Triandaru, S., Budisantoso, T. 2009. Bank dan Lembaga Keuangan Lain. Salemba Empat. Jakarta. 